\title{
Innervated Cross-Finger Pulp Flap for Reconstruction of the Fingertip
}

\author{
Nae-Ho Lee, Woo-Sik Pae, Si-Gyun Roh, Kwang-Jin Oh, Chung-Sang Bae, Kyung-Moo Yang \\ Department of Plastic and Reconstructive Surgery, Chonbuk National University Medical School, Jeonju, Korea
}

Background Fingertip injuries involving subtotal or total loss of the digital pulp are common types of hand injuries and require reconstruction that is able to provide stable padding and sensory recovery. There are various techniques used for reconstruction of fingertip injuries, but the most effective method is functionally and aesthetically controversial. Despite some disadvantages, cross-finger pulp flap is a relatively simple procedure without significant complications or requiring special techniques.

Methods This study included 90 patients with fingertip defects who underwent cross-finger pulp flap between September 1998 and March 2010. In 69 cases, neurorrhaphy was performed between the pulp branch from the proper digital nerve and the recipient's sensory nerve for good sensibility of the injured fingertip. In order to evaluate the outcome of our surgical method, we observed two-point discrimination in the early ( 3 months) and late (12 to 40 months) postoperative periods.

Results Most of the cases had cosmetically and functionally acceptable outcomes. The average defect size was $1.7 \times 1.5 \mathrm{~cm}$. Sensory return began 3 months after flap application. The twopoint discrimination was measured at $4.6 \mathrm{~mm}$ (range, 3 to $6 \mathrm{~mm}$ ) in our method and $7.2 \mathrm{~mm}$ (range, 4 to $9 \mathrm{~mm}$ ) in non-innervated cross-finger pulp flaps.

Conclusions The innervated cross-finger pulp flap is a safe and reliable procedure for lateral oblique, volar oblique, and transverse fingertip amputations. Our procedure is simple to perform under local anesthesia, and is able to provide both mechanical stability and sensory recovery. We recommend this method for reconstruction of fingertip injuries.

Keywords Finger injuries / Subcutaneous tissue / Microsurgery / Nerve transfer
Correspondence: Si-Gyun Roh Department of Plastic and Reconstructive Surgery, Chonbuk National University Medical School, 20 Geonji-ro, Deokjin-gu, Jeonju 561-712, Korea

Tel: $+82-63-250-1860$

Fax: +82-63-250-1866

E-mail: pssroh@jbnu.ac.kr
This paper was supported by research funds from Research Institute of

Clinical Medicine of Chonbuk National University in 2008.

No potential conflict of interest relevant to this article was reported.

\section{INTRODUCTION}

Fingertips are parts of the human body that are always exposed to the external environment and play an important role in feeling delicate sensations. Anatomically, thickness of the epidermis and the dermis is 2 to $3 \mathrm{~mm}$, and the epidermis is composed of cornified, stratified, squamous epithelium. Dense connective tissues and numerous fibrous septa connect between the skin and the synovium and increase the fingertips' durability and function as cushions. These structures prevent the skin from slipping when pinching an object $[1,2]$. Similar tissue must be obtained in order to reconstruct the fingertips, and the primary concern in reconstruction must be recovery of sensation. Therefore, it is important to select the optimal surgical method considering the patients' age, sex, occupation, and the importance of the injured finger [2-5]. 
Treatment of fingertip injuries should take into consideration proper maintenance of the soft tissues, restoration to normal length, prevention of fingernail deformity, recovery of normal sensation without pain, and reconstruction within a minimal length of time with maximal functional and cosmetic satisfaction $[2,4,6,7]$. The best treatment would be surgery using the simplest method with similar tissue and possibly leaving minimal damage to the donor site. The methods of fingertip reconstruction are local flaps such as volar V-Y advancement flap, regional flaps such as cross-finger and neurovascular island flap, distant flaps like groin flap, and a free flap using the toes [2].

The authors used innervated cross-finger pulp flap for fingertip reconstruction from September 1998 to March 2010 in 69 patients. We also had 21 cases of non-innervated, cross-finger pulp flap as the control group to compare the degree of nerve regeneration.

\section{METHODS}

From September 1998 to March 2010, we reconstructed fingertip defects in 90 patients who had soft tissue defects or bone exposure due to fingertip injuries. There were 53 males and 37 females with an average age of 46 years (range, 3 to 76 years). There were 43 cases of middle finger injuries, which was the highest number of injuries, and right hand injury was predominant. The most common cause of injury was crushing injuries by machine compression. Other causes included cutting machines, fruit knives, electric saws, and bite injuries. The control group included 21 patients who had received non-innervated cross-finger pulp flap, and the experimental group included 69 patients who received innervated cross-finger pulp flap. The operation time, patient satisfaction, and recovery of sensation were compared between the

\section{Fig. 1. Illustration of the operative method}

Epineural neurorrhaphy between the pulp branch of the flap and injured finger.

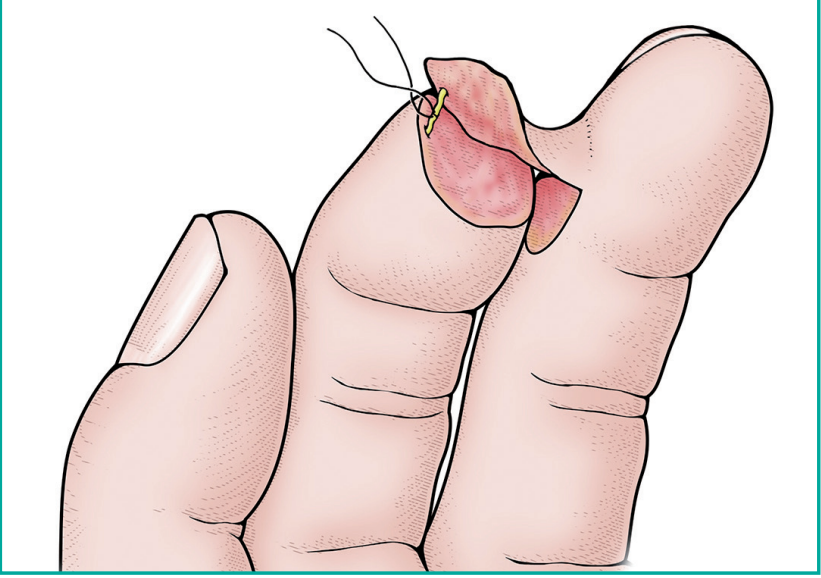

two groups. We observed two-point discrimination, stiffness of the involved joint, cold intolerance, hypersensitivity, numbness, and pain. The follow-up averaged 24 months (range, 12 to 40 months).

Except for the 12 pediatric patients, the operations were performed under local anesthesia. We tied a tourniquet around each patient's upper arm, cleansed the operation site, and debrided the necrotic tissue on the fingertip. At the same time, we manipulated the pressure of the tourniquet to check the condition of the fingertip vessels. We used rubber bands for 15 to 20 minutes to compress the distal finger for the patients who complained of pain caused by the tourniquet.

The flap was commonly designed on the opposite pulp area of the adjacent finger and over $2 \mathrm{~mm}$ away from the nail wall. When the depth of the defect was deep, a sufficient amount of subcutaneous fat layer and arterioles were included in the donor flap when it was elevated. For small defects, a random cutaneous flap was used. After flap elevation, a full thickness skin graft was performed for the coverage of the defect site, and then a tie-over dressing was applied. When we selected the donor site for a full thickness skin graft, the graft was obtained from the hypothenar area if the defect size was under $1 \mathrm{~cm}$, and the graft was obtained from the medial plantar area or the wrist crease if the width of defect size was above $1 \mathrm{~cm}$.

To improve sensory restoration, the pulp branch from the proper digital nerve was dissected under a microscope and transferred, with the nerve temporarily sutured, to the defected area. A neurorrhaphy was performed between the pulp branch from proper digital nerve and the recipient's sensory nerve with 11-0 nylon sutures (Figs. 1, 2).

After the elevated flap was sutured to the recipient site with 6-0 nylon sutures, an anchoring 4-0 nylon suture was applied

\section{Fig. 2. Illustration of the operative method}

The joined nerves are tucked into the wound and the remainder of the flap margin, and all of the wounds are sutured.

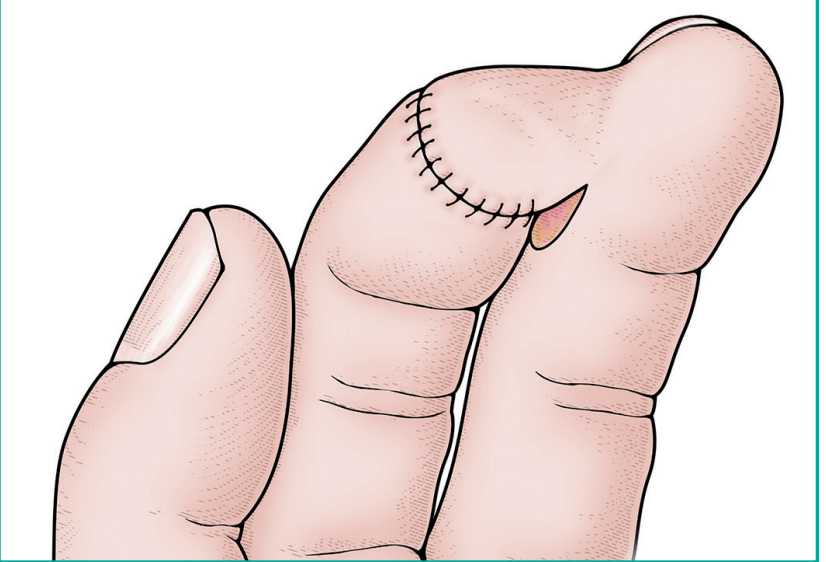


between the connected fingers for flap immobilization. A tieover dressing was opened on the 3 rd postoperative day. Postoperative dressing was applied every 2 to 3 days. Flap detachment was performed after 9 to 10 days.

\section{Case 1}

A 27-year-old male was admitted with a crushing injury of the left index finger caused by a press machine. The patient had $1 / 4$ of the distal phalanx amputated, and the wound surface was severely crushed, and therefore, impossible to replant. Because the wound surface was too wide and deep, we decided to perform an innervated cross-finger pulp flap using the radial side of the middle finger as the donor site. We elevated a $2.2 \times 1.3 \mathrm{~cm}$ flap with the sensory nerve. The sensory nerve was anastomosed in the center of the flap and the defect area. The two-point discrimination was $4.4 \mathrm{~mm}$ at 12 months after surgery. No complications such as scar contracture or depression were noted on the donor site (Figs. 3, 4).

\section{Case 2}

A 35-year-old male was admitted with a right index fingertip

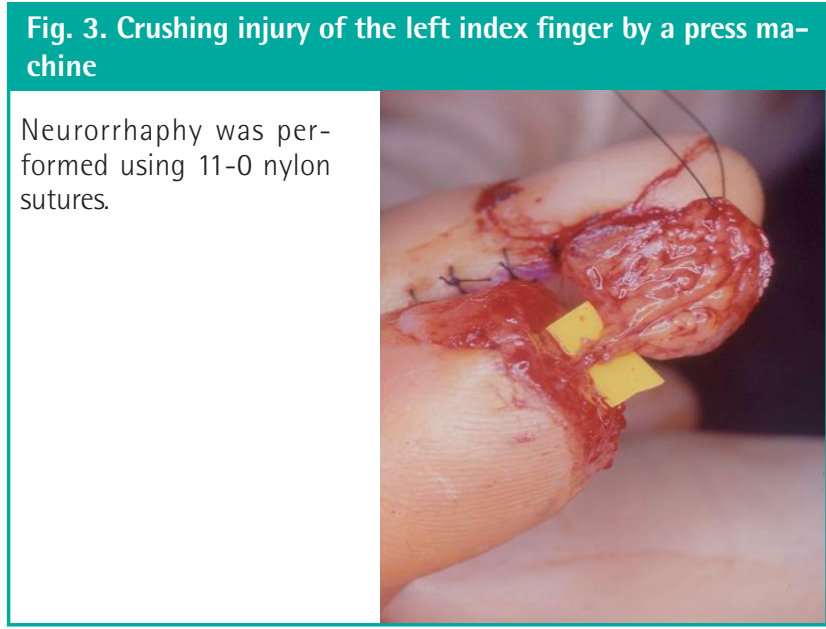

\section{Fig. 4. Intraoperative view}

Innervated cross-finger pulp flap was performed using the radial side of the middle finger as the donor site. injury caused by compression from a heavy object. The distal phalange was partially amputated, and the bone was exposed. Because the wound surface was slanted towards the ulnar side, we concluded that it would be better to use the radial part of the middle finger as the donor site. We designed a $1.9 \times 1.7 \mathrm{~cm}$ axial cutaneous flap and elevated it with the cortical pulp branch. A full thickness skin graft for the donor site was performed and

Fig. 5. Crushing injury of the right index finger by a heaby object

Right index fingertip injury caused by compression from a heavy object. The distal phalanx was partially amputated and the bone was exposed.

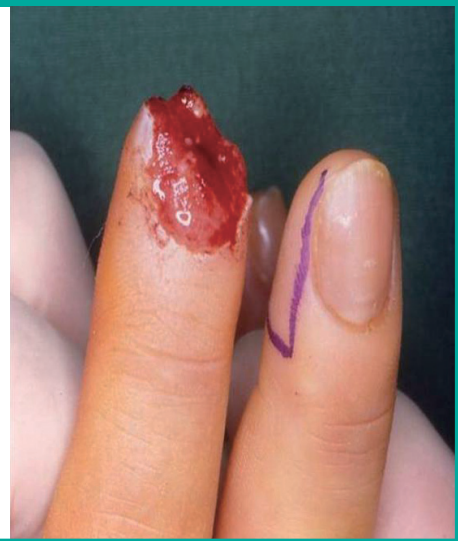

Fig. 6. Intraoperative view

A $1.9 \times 1.7 \mathrm{~cm}$ axial cutaneous flap was elevated, and neurorrhaphy was performed using 11-0 nylon sutures.

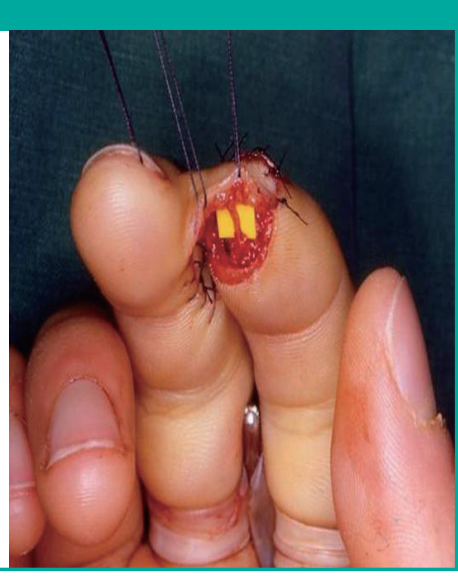

\section{Fig. 7. Postoperative follow-up view}

Follow-up view showing the healed flap with good contour in the index finger. 
then a neurorrhaphy was conducted using 11-0 nylon sutures. The patient's two-point discrimination test was $4.4 \mathrm{~mm}$ at 18 months after surgery, and the patient was satisfied with the cosmetic results (Figs. 5-7).

\section{RESULTS}

We reconstructed the fingertips of 90 patients with soft tissue defects and bone exposure accompanied by fingertip injuries using cross-finger pulp flap. We used non-innervated cross-finger pulp flap in 21 patients and innervated cross-finger pulp flap in $69 \mathrm{pa}-$ tients. The flaps survived in all of the cases and showed satisfactory progress regardless of the width and length of the flap. The size of the flaps were $1 \times 0.8 \mathrm{~cm}$ to $2.3 \times 1.4 \mathrm{~cm}$. The full thickness skin grafts for covering the donor site were taken up well, and cosmetically, they were satisfactory. In all of the cases, primary closure of the donor site for the full thickness skin graft was possible, and the mean surgical duration was 48 minutes.

In the cases with non-innervated cross-finger pulp flap, the recovery of sensation was poor when compared with the cases with innervated cross-finger pulp flap. The two-point discrimination test and Semmes-Weinstein monofilament test was administered 12 months after surgery and resulted in a mean distance of $7.2 \mathrm{~mm}$ and kit sizes between 4.08 and 4.56, respectively, which showed recovery of sensation (Table 1). Dryness of the flap was also observed. On the other hand, in cases with innervated cross finger pulp flap, we observed recovery of sensation 3 months after surgery and improvement in Tinel's sign. The two-point discrimination test and Semmes-Weinstein monofilament test were administered 12 months after surgery and resulted in a mean distance of $4.6 \mathrm{~mm}$ and kit sizes between 3.22 and 3.84, respectively (Table 2 ). There was a statistically significant difference in the sensory recovery between the two groups $(\mathrm{P}=0.001)$. Consequently, we had confidence that the final outcome of our method (cross-finger pulp flap with neurorrhaphy) was much better than the other method (non-innervated, cross-finger pulp flap) for sensory recovery.

We did a satisfaction survey of 90 patients after the operation. Both the experimental and control groups were satisfied with the cosmetic outcomes except for 5 cases. In the control group, 12 of the 21 patients complained of an imbalance occurring when using pencils or chopsticks. On the other hand, patients who had fingertips reconstructed with innervated, cross-finger pulp flap did not complain about any aspects of their everyday life.

Joint stiffness as a result of immobilization for flap stability was present temporarily and resolved completely during physical therapy. There was no impairment of joint movement.

Cold intolerance was present in 15 patients at the end of the

\begin{tabular}{|c|c|c|c|}
\hline $\begin{array}{l}\text { Patient } \\
\text { No. }\end{array}$ & Age/Sex & $\begin{array}{l}\text { Two point } \\
\text { discrimination } \\
\text { test }(\mathrm{mm})\end{array}$ & $\begin{array}{c}\text { Semmes-Weinstein } \\
\text { monofilament test } \\
{\text { (kit number) })^{\text {a) }}}^{\text {(kit }}\end{array}$ \\
\hline 1 & $35 / M$ & 4 & 4.08 \\
\hline 2 & $37 / F$ & 5.9 & 4.31 \\
\hline 3 & $15 / M$ & 7.8 & 4.31 \\
\hline 4 & $67 / M$ & 7.9 & 4.56 \\
\hline 5 & $55 / M$ & 6.8 & 4.08 \\
\hline 6 & $3 / F$ & 6.4 & 4.56 \\
\hline 7 & $11 / F$ & 5.8 & 4.31 \\
\hline 8 & $45 / M$ & 7.3 & 4.31 \\
\hline 9 & $37 / M$ & 8.6 & 4.56 \\
\hline 10 & $39 / M$ & 7.9 & 4.56 \\
\hline 11 & $46 / M$ & 7.2 & 4.31 \\
\hline 12 & $37 / F$ & 7.7 & 4.08 \\
\hline 13 & $58 / F$ & 9 & 4.56 \\
\hline 14 & $56 / M$ & 6.9 & 4.08 \\
\hline 15 & 10/F & 8.4 & 4.74 \\
\hline 16 & $47 / M$ & 6.7 & 4.31 \\
\hline 17 & $41 / F$ & 7.2 & 4.56 \\
\hline 18 & $27 / M$ & 7.9 & 4.08 \\
\hline 19 & $37 / F$ & 7.6 & 4.56 \\
\hline 20 & $31 / \mathrm{M}$ & 7.3 & 4.31 \\
\hline 21 & $56 / M$ & 6.9 & 4.08 \\
\hline
\end{tabular}

follow-up, and the two-point discrimination was above average in those patients.

Scar contracture of the full thickness skin graft of the donor site was minimal. We were also able to avoid sensory loss of the donor fingertip by using pulp sensory nerves branching from the digital nerves. The scar of the hypothenar region, which was the donor site of the full thickness skin graft, was inconspicuous and the patients did not feel any discomfort in performing the activities of daily living.

\section{DISCUSSION}

In various types of fingertip injuries, microsurgical replantation is most effective in cases of complete amputation below the distal interphalangeal joints. Unfortunately, fingertip injuries that are accompanied by severe crushing injuries are technically not suitable for microsurgical replantation, but other modified methods have been introduced. Applying local flaps to small defects is an unarguably simple procedure and it is superior for sensory recovery. However, free flap using the tissues of the plantar area and the toes is currently preferred in cases with larger defects and in cases that need reconstruction of the fingernails $[2,4,8,9]$. We use distant flaps for the cases that are not suitable for free flaps. For the cases with a local flap and undergoing a larger operation such as free flap, which is impossible to perform due to the site 
Table 2. Patients with neurorrhaphy

\begin{tabular}{|c|c|c|c|c|c|c|c|}
\hline $\begin{array}{l}\text { Patient } \\
\text { No. }\end{array}$ & Age/Sex & $\begin{array}{l}\text { Two point } \\
\text { discrimination } \\
\text { test }(\mathrm{mm})\end{array}$ & $\begin{array}{l}\text { Semmes-Weinstein } \\
\text { monofilament test } \\
\text { (kit number) }^{\text {a) }}\end{array}$ & $\begin{array}{l}\text { Patient } \\
\text { No. }\end{array}$ & Age/Sex & $\begin{array}{l}\text { Two point } \\
\text { discrimination } \\
\text { test }(\mathrm{mm})\end{array}$ & $\begin{array}{c}\text { Semmes-Weinstein } \\
\text { monofilament test } \\
\text { (kit number) }^{\text {a) }}\end{array}$ \\
\hline 1 & $25 / M$ & 3.0 & 3.84 & 36 & $59 / F$ & 4.5 & 3.22 \\
\hline 2 & $76 / \mathrm{M}$ & 4.6 & 3.61 & 37 & $63 / M$ & 3.9 & 3.84 \\
\hline 3 & $5 / \mathrm{M}$ & 5.3 & 3.22 & 38 & $66 / F$ & 4.7 & 3.22 \\
\hline 4 & $7 / M$ & 4.8 & 3.61 & 39 & $54 / M$ & 4.9 & 3.84 \\
\hline 5 & $69 / F$ & 4.9 & 3.84 & 40 & $34 / M$ & 4.9 & 3.61 \\
\hline 6 & $71 / \mathrm{F}$ & 3.7 & 3.22 & 41 & $28 / M$ & 5.4 & 3.22 \\
\hline 7 & $67 / M$ & 4.2 & 3.22 & 42 & $18 / F$ & 5.1 & 3.84 \\
\hline 8 & 69/F & 5.5 & 3.84 & 43 & $67 / F$ & 4.7 & 3.22 \\
\hline 9 & $65 / M$ & 5.6 & 3.61 & 44 & $53 / \mathrm{M}$ & 4.2 & 3.61 \\
\hline 10 & $45 / F$ & 5.1 & 3.84 & 45 & $48 / M$ & 4.5 & 3.22 \\
\hline 11 & $43 / M$ & 4.7 & 3.22 & 46 & $27 / M$ & 5.7 & 3.84 \\
\hline 12 & $49 / F$ & 4.1 & 3.61 & 47 & $58 / F$ & 5.3 & 3.61 \\
\hline 13 & $51 / F$ & 4.2 & 3.61 & 48 & $60 / M$ & 4.6 & 3.84 \\
\hline 14 & $37 / \mathrm{M}$ & 4.9 & 3.84 & 49 & $52 / \mathrm{M}$ & 4.2 & 3.61 \\
\hline 15 & $70 / F$ & 5.2 & 3.22 & 50 & $37 / F$ & 4.3 & 3.84 \\
\hline 16 & $63 / F$ & 4.6 & 3.84 & 51 & $58 / \mathrm{M}$ & 4.1 & 3.22 \\
\hline 17 & $62 / \mathrm{M}$ & 4.9 & 3.84 & 52 & $18 / F$ & 4.9 & 3.61 \\
\hline 18 & $16 / \mathrm{M}$ & 5.0 & 3.22 & 53 & $38 / F$ & 3.9 & 3.84 \\
\hline 19 & $37 / M$ & 4.1 & 3.61 & 54 & $54 / F$ & 4.2 & 3.61 \\
\hline 20 & $49 / M$ & 4.4 & 3.84 & 55 & $67 / M$ & 4.9 & 3.22 \\
\hline 21 & 52/M & 4.9 & 3.22 & 56 & $49 / F$ & 4.4 & 3.61 \\
\hline 22 & $39 / F$ & 5.1 & 3.22 & 57 & $32 / \mathrm{M}$ & 3.9 & 3.22 \\
\hline 23 & $40 / F$ & 4.1 & 3.84 & 58 & $48 / M$ & 3.9 & 3.84 \\
\hline 24 & $27 / M$ & 3.5 & 3.61 & 59 & $66 / M$ & 3.9 & 3.22 \\
\hline 25 & $28 / F$ & 4.3 & 3.22 & 60 & $49 / F$ & 4.7 & 3.61 \\
\hline 26 & $43 / \mathrm{M}$ & 5.1 & 3.84 & 61 & $76 / F$ & 4.2 & 3.22 \\
\hline 27 & $49 / F$ & 6.0 & 3.84 & 62 & $54 / \mathrm{M}$ & 4.6 & 3.84 \\
\hline 28 & $45 / M$ & 4.7 & 3.61 & 63 & $67 / M$ & 4.1 & 3.22 \\
\hline 29 & $52 / F$ & 4.3 & 3.84 & 64 & $68 / M$ & 4 & 3.61 \\
\hline 30 & $29 / F$ & 4.8 & 3.22 & 65 & $33 / \mathrm{M}$ & 4.8 & 3.22 \\
\hline 31 & $19 / M$ & 4.8 & 3.22 & 66 & $28 / M$ & 4.9 & 3.61 \\
\hline 32 & $58 / F$ & 5.2 & 3.84 & 67 & $64 / \mathrm{M}$ & 4.7 & 3.84 \\
\hline 33 & $57 / F$ & 5.1 & 3.61 & 68 & $58 / \mathrm{M}$ & 4.2 & 3.61 \\
\hline 34 & $72 / \mathrm{M}$ & 4.1 & 3.22 & 69 & $56 / M$ & 4.1 & 3.22 \\
\hline 35 & $57 / F$ & 5.3 & 3.84 & & & & \\
\hline
\end{tabular}

and size of the defect, we apply a neurovascular island flap or cross-finger flap.

However, some of the weaknesses of the neurovascular island flap are that one side of the proper digital artery must be sacrificed and sensory recovery is relatively poor. Likewise, noninnervated cross-finger pulp flap also has the weakness of poor sensory recovery [8,9]. In 1983, Cohen and Cronin [10] first performed innervated cross-finger flap to overcome these weaknesses. They anastomosed between the dorsal sensory branch and the pulp branch. A two-point discrimination test resulted in $4.8 \mathrm{~mm}$, which was within a satisfactory range, but solidity and durability decreased when the patients pinched an object because dorsal skin was used, which was different from the pulp tissue $[10,11]$.

Many other authors have strenuously insisted on the advantages of sensory reconstruction for fingertip injuries. For instance, Ozdemir et al. [12] presented innervated dorsal adipofascial turnover flap for fingertip amputations and claimed the procedure had the advantage of sensory recovery without functional or aesthetic disturbance at the donor site. Lassner et al. [13] presented sensory reconstruction of the fingertip using the bilaterally innervated, sensory cross-finger flap and reported good functional results, especially in sensory recovery. In addition, $\mathrm{Li}$ and Cui [14] presented the advantage of his surgical technique, innervated reverse island flap based on the end dorsal branch of the digital artery, for fingertip reconstruction. Our authors referred to these studies and designed a modified innervated cross-finger pulp flap using the pulp tissue of the fingertip area as the donor site to overcome these shortcomings.

Our method resulted in a two-point discrimination of $4.6 \mathrm{~mm}$, 
a Semmes-Weinstein monofilament test of between 3.22 and 3.84 , and a satisfactory radius of rotation, which enabled the surgeons to cover the defects of the fingertips and the front and lateral side of the pulp area without difficulties. This method is also advantageous because it is a simple method that can be performed with local anesthesia and it is able to reduce the surgical duration and leaves minimal scarring on the donor site.

An objective method for measuring the degree of sensory recovery after covering fingertip defects is the two-point discrimination test and Semmes-Weinstein monofilament test [11]. Patients should have a result of $8 \mathrm{~mm}$ or less in order to obtain satisfactory function of the fingertip. Sensory recovery is greater and faster in younger patients, and careful observation is required for 12 months after surgery. As a result, to improve sensory recovery, maximal amounts of subcutaneous tissue must be included in the neurovascular island dissection, compression must be avoided, and the tension of the island flap and approach to each nerve ending must be accurate during neurorrhaphy [8-11].

\section{REFERENCES}

1. Johnson RK, Iverson RE. Cross-finger pedicle flaps in the hand. J Bone Joint Surg Am 1971;53:913-9.

2. Kappel DA, Burech JG. The cross-finger flap. An established reconstructive procedure. Hand Clin 1985;1:677-83.

3. Miura T. Thumb reconstruction using radial-innervated cross-finger pedicle graft. J Bone Joint Surg Am 1973;55: 563-9.
4. Spokevicius S, Gupta A. The modified cross finger flap for finger pulp and nail bed reconstruction. J Hand Surg $\mathrm{Br}$ 1997;22:745-9.

5. Cronin TD. The cross finger flap: a new method of repair. Am Surg 1951;17:419-25.

6. Gurdin M, Pangman WJ. The repair of surface defects of fingers by trans-digital flaps. Plast Reconstr Surg (1946) 1950;5:368-71.

7. Fisher RH. The Kutler method of repair of finger-tip amputations. J Bone Joint Surg Am 1967;49:317-21.

8. Joshi BB. A sensory cross-finger flap for use on the index finger. Plast Reconstr Surg 1976;58:210-3.

9. El-Khatib H. Adipofascial axial pattern cross-finger flap. Plast Reconstr Surg 1996;97:850-3.

10. Cohen BE, Cronin ED. An innervated cross-finger flap for fingertip reconstruction. Plast Reconstr Surg 1983;72:688-97.

11. Markley JM Jr. The preservation of close two-point discrimination in the interdigital transfer of neurovascular island flaps. Plast Reconstr Surg 1977;59:812-6.

12. Ozdemir R, Kilinc H, Sensoz O, et al. Innervated dorsal adipofascial turnover flap for fingertip amputations. Ann Plast Surg 2001;46:9-14.

13. Lassner F, Becker M, Berger A, et al. Sensory reconstruction of the fingertip using the bilaterally innervated sensory cross-finger flap. Plast Reconstr Surg 2002;109:988-93.

14. Li YF, Cui SS. Innervated reverse island flap based on the end dorsal branch of the digital artery: surgical technique. J Hand Surg Am 2005;30:1305-9. 